\title{
THE SECTIONS OF THE FIRST WORLD CONFERENCE ON MEDICAL EDUCATION
}

We invited the Vice-Presidents of the Conference to present brief statements on the subjects of the sections they presided over this week, and these are printed below under the headings of each of the four sections.

\section{REQUIREMENTS FOR ENTRY INTO MEDICAL SCHOOLS} THE SELECTION OF STUDENTS

\author{
BY
}

\section{VICTOR JOHNSON, M.D., Ph.D. Mayo Foundation for Medical Education and Research, Rochester, Minnesota, U.S.A.}

No greater responsibility devolves upon medical educators than that of determining who are qualified to study medicine and who are not. I am sure that any evaluation of the results of these selective efforts by those who exercise such responsibility would be characterized by extreme modesty, if not humility. All will admit that errors in judgment have excluded from medicine some who are qualified to become physicians and have included some who should not enter medicine.

Section A of the First World Conference on Medical Education addresses itself to this problem to the end that world-wide experience may help achieve a closer approximation to the ideal goal. Certain qualifications of potential medical students are relatively easy to measure, while others are virtually impossible to determine.

It is granted that acceptable candidates must be intelligent and that we can measure that intelligence with a degree of accuracy by various testing devices, examinations, and the academic performance of the applicant. But how may we be satisfied that a candidate couples emotional stability with his intelligence? I believe it remains to be demonstrated that brilliance is more likely than mediocrity to be associated with emotional instability. Yet we have all seen too many examples of intellectually able medical students whose lack of stability unfits them to be medical students and physicians of a high order. May we eventually be able to determine emotional stability as effectively as we can determine intelligence?

\section{Motivation}

Again, let us suppose our candidate possesses the aptitude for science and medicine. Although aptitude tests may be less reliable than those of intelligence, we can probably arrive at a reasonable approximation to the truth by appropriate means. But is the aptitude joined with proper motivation ? Is our student possessed of a drive toward medicine that cannot be denied ? Has he a single-minded devotion to his work as a student, a house officer, and a physician so that the many denials to himself are fully compensated by the gratifications of his chosen tasks? The arduous job of studying medicine leaves no room for less than wholehearted effort.

A misdirected apparent orientation towards medicine, of which the student himself may be unaware, may stubbornly defy detection. I do not refer to the simple case of the intelligent, apt candidate who says, "My father always wanted me to study medicine, but I do not." His case is easy. Also, he is rare. More common is the misfit student who fully believes he is properly motivated. He says, "My father always wanted me to study medicine, and $I$ also have always desired it." The parent may have exerted no obvious direct influence, but in numberless unplanned indirections pointed the son's career toward medicine. How to detect real from fancied strong motivation is a challenge. Often the defect manifests itself only by a failure to master the work of the medical school, following painful efforts to succeed.

The coupling of intelligence with emotional stability, and of aptitude with motivation, requires further sound character and lofty ideals, objectivity tempered with warm kindliness, and industry born of devotion to work. Perhaps these attributes may never be measurable. Yet we must never cease trying.

It would be well if we could estimate these desiderata of a medical student and physician even before he has completed his premedical studies, but not, in my opinion, for the reason commonly given. We are told that a very early knowledge of a student's qualifications for the later study of medicine might save him future disappointment, and also prevent him from "wasting time" in premedical studies instead of pursuing another line of education. I agree with the desirability of avoiding disappointment, but I have little sympathy with the "wasted time" concept, unless education for life is wasted time for the would-be physician.

The kind of education which best prepares a student for medical school also prepares him well for other pursuits. In such general education I would include natural science prominently. To-day it is fashionable, at least in the United States, for advisers of potential medical students to say, "Premedical students should not take too many science studies ; they should acquire a good general education," as if education in natural science were of a lower order culturally than is education in the humanities or social sciences. Such educational advisers of to-day are akin to certain of the humanists of the past, who dismissed, without ceremony, science as a factor in general education. Thomas Huxley (1899) called them "Levites in chaige of the ark of culture and monopolists of liberal euucation." He decried the accepted reference to the Renaissance as the "Revival of Letters," saying "... as if the influences then brought to bear upon the mind of Western Europe had been whol'y exhausted in the field of literature. I think it is commonly forgotten that the revival of science... was not less momentous."

Perhaps a legitimate reason why a student should not devote too much time to science in his preparatory studies is that by limiting the time he devotes to the humanities he may never appreciate that the humanities have no more proprietary claim than does science upon the dramatic, the imaginative, the beautiful. No epic poem displays a majestic sweep excelling that of Darwin's evolutionary history. The balance and perfection of composition of a painting are equally apparent in what Walter Cannon called "The Wisdom of the Body."

The burden of my thought is that we regard science, and teach science to prospective physicians, without apology for its utilitarianism, and as an indispensable ingredient of human culture.

\section{Conclusion}

Let us venture the hope that this conference may contribute some measure of advance towards a better selection of those most qualified to become physicians, who possess not only intelligence but emotional stability, not only aptitude but motivation, not only industry but warmth and kindliness. Let us further hope that we may make some progress toward an improved preliminary training of future physicians ; an education which includes the humanities and the social sciences, and also gives prominence to the natural sciences, not merely as pragmatic tools, but as an indispensable ingredient of the cultural development of a physician, a lawyer, a clergyman, or any other productive citizen of the modern world.

REFERENCE
Huxley, T. H. (1899). Science and Education Essays, p. 134. Appleton, 